\title{
Characteristics of First-Year Residents in Top-Ranked United States Ophthalmology Residency Programs
}

\author{
John C. Lin ${ }^{1,2}$ Anagha Lokhande, BA ${ }^{2}$ \\ Paul B. Greenberg, MD, MPH ${ }^{2,5}$
}

Address for correspondence Paul B. Greenberg, MD, MPH, Division of Ophthalmology, Brown University, Coro Center West, 1 Hoppin St, Suite 200, Providence, RI 02903

(e-mail: paul_greenberg@brown.edu).

\begin{abstract}
\section{Keywords}

- ophthalmology

- residency

- residency match

- research productivity
\end{abstract}

Objective The aim of the study is to investigate the characteristics of first-year residents associated with attending a top-ranked United States (U.S.) ophthalmology residency program over the past decade.

Methods First-year ophthalmology residents in 2009, 2013, 2016, and 2019 were identified from institutional websites, Doximity, Linkedln and the Wayback Machine. Publications were obtained from Scopus and Google Scholar; research productivity was measured using the $h$-index, and medical school region based on U.S. Census Bureau designations. Medical school and ophthalmology training program rankings were based on U.S. News \& World Report (U.S. News) rankings and National Institutes of Health (NIH) funding. One-way ANOVA, Wilcoxon rank sum, $\chi^{2}$, and $t$-tests were used to analyze trends, and odds ratios (ORs) were calculated using logistic regression.

Results Data were obtained on $81 \%(1,496 / 1,850)$ of the residents; $43 \%$ were female; $5 \%$ were international medical graduates (IMGs); and $10 \%$ had other graduate degrees. Over the decade, the mean $h$-index increased $(0.87-1.26 ; p<0.05)$ and the proportion of residents who attended a top 20 medical school decreased (28-18\%; $p<0.05)$. In a multivariate logistic regression model, characteristics associated with being a first-year resident in a top 20 program ranked by U.S. News were female gender [OR: 1.32, 95\% $\mathrm{Cl}: 1.02-1.72$ ], having a Master's degree [OR: $2.28,95 \% \mathrm{Cl}: 1.29-4.01]$ or PhD [OR: 2.23, 95\% Cl: 1.32-3.79], attending a top 20 [OR: 5.26 , 95\% Cl: 3.66-7.55] or a top 40 medical school by NIH funding [OR: $2.45,95 \% \mathrm{Cl}: 1.70-3.54]$, attending a medical school with a mean USMLE Step 2 score above 243 [OR: 1.64, 95\% Cl: 1.01-2.67] or located in the Northeast [OR: $2.00,95 \% \mathrm{Cl}: 1.38-2.89]$ and having an $h$-index of one or more [OR: 1.92, 95\% Cl: 1.47-2.51]. Except for gender, these characteristics were also received

March 15, 2021 accepted after revision July 21, 2021
DOI https://doi.org/ $10.1055 / \mathrm{s}-0041-1735152$. ISSN 2475-4757.

\footnotetext{
(C) 2022. The Author(s).

This is an open access article published by Thieme under the terms of the Creative Commons Attribution-NonDerivative-NonCommercial-License, permitting copying and reproduction so long as the original work is given appropriate credit. Contents may not be used for commercial purposes, or adapted, remixed, transformed or built upon. (https://creativecommons.org/ licenses/by-nc-nd/4.0/) Thieme Medical Publishers, Inc., 333 Seventh Avenue, 18th Floor, New York, NY 10001, USA
} 
significantly associated with matching to a top 20 ophthalmology program by NIH funding.

Conclusion Female gender, graduate degrees, research productivity, and attending a medical school with high research productivity, high mean USMLE Step 2 score or in the Northeast were key characteristics of first-year residents in top-ranked U.S. ophthalmology residency programs.

In the United States (U.S.), ophthalmology is one of the most competitive specialties for residency applicants. ${ }^{1,2}$ Residency program research productivity and prestige are weighed heavily by applicants, especially those interested in pursuing a fellowship or academic career. ${ }^{3}$ However, there is a dearth of studies investigating multiple characteristics-such as demographic and medical school characteristics-associated with matching to a top-ranked ophthalmology residency program.

Research experience is often touted as important for prospective applicants and has been linked to post-residency academic productivity ${ }^{4}$ but its precise role in the ophthalmology match has not been well defined. ${ }^{5-7}$ A 2018 study analyzed research productivity among matriculated residents; however, it focused on 1 year of student publications from a single database without assessing other applicant characteristics. ${ }^{5}$ Other studies investigating characteristics associated with matching in ophthalmology did not include research productivity and relied on decade-old data (20032008, 2011). ${ }^{1,8}$ Broadening our baseline understanding of characteristics that impact the ophthalmology match will allow program directors to better assess applicants' qualifications relative to their peers, inform medical school faculty advisors, ${ }^{9}$ and help medical students improve their candidacy for an ophthalmology residency spot.

This study has two specific objectives: to describe the characteristics of first-year ophthalmology residents for the past decade and to investigate characteristics associated with obtaining a position in a top-ranked ophthalmology residency program.

\section{Methods}

The Brown University Institutional Review Board determined this study did not meet the definition of human participants research and did not require formal review.

\section{Data Collection}

This study analyzed data from first-year (post-graduate year two; PGY-2) residents listed on the websites of U.S. ophthalmology residency programs accredited by the Accreditation Council for Graduate Medical Education (ACGME). The Internet Archive Wayback Machine was used to identify PGY-2 residents listed on individual program websites in 2009, 2013, and 2016 and 2019. ${ }^{10}$ Demographic information (gender, graduate degrees, medical schools) was recorded for each resident. When necessary, Doximity and LinkedIn were searched for additional information on the residents. ${ }^{11,12}$

Resident publication profile was used as a proxy for research productivity when they were medical students. The full names of the PGY-2 residents were searched in Scopus for English language articles they published as students up until their residency interviews (e.g., for 2019 PGY2 residents, the search would end on December 31, 2017). There were two criteria for determining authorship when the PGY-2 residents were students, as described by Wadhwa et $\mathrm{al}^{13}$ : (1) an accurate institutional affiliation for the author; and (2) authorship at an institution with which the student was affiliated. Original research articles, reviews, and case reports were recorded; book chapters, conference presentations, posters, and abstracts were excluded.

The type of publication (original research, review article, or case report) and the number of first-authored, ophthalmology-related, and other (clinical and basic science) publications were recorded for each PGY-2 resident. In addition, the $h$-index and $m$-quotient of each resident were calculated as measures of publication productivity. The $h$-index takes into account the number of publications and number of citations; the $m$ quotient adjusts the $h$-index based on the time since the researcher began publishing, allowing for an accurate comparison among researchers with different durations of experience. ${ }^{14}$ Nonscientific publications were excluded.

Mean United States Medical Licensing Examination (USMLE) Steps 1 and 2 scores were also obtained from U.S. News and World Report (U.S. News) and included in the analysis to identify their relative importance in the residency match, especially given the planned change to pass/fail grading for Step $1 .{ }^{15,16}$ The medical school and residency program regions were defined according to the U.S. Census Bureau. ${ }^{17}$

Medical schools were classified into three tiers based on 2021 U.S. News medical school research rankings and on summed 2017 to 2019 National Institutes of Health (NIH) funding: top 20, top 40, and all other medical schools. The U.S. News rankings were used as a proxy for a medical school's reputation, ${ }^{18}$ and NIH funding for research productivity. ${ }^{19,20}$ Ophthalmology residency programs were stratified into two tiers based on 2021 U.S. News ophthalmology hospital rankings and NIH funding from 2017 to 2019: top 20 and all other programs. The 2021 U.S. News rankings were partially based on medical school data from 2017 to 2019 and were used for residents from all years as U.S. News does not publish their rankings from previous years; the same years of data were extracted for NIH funding for consistency. ${ }^{18}$ 
Our primary outcome was first-year resident characteristics associated with being in a top 20 ophthalmology program based on program' reputation (U.S. News rankings). We also assessed resident characteristics associated with being in a top 20 ophthalmology program based on programs' research productivity (NIH funding).

\section{Data Analysis}

Statistical analyses were conducted using Stata (StataCorp, College Station, TX). ${ }^{21}$ Descriptive statistics, student $t$-tests, and $\chi^{2}$ tests were used to compare demographic and research characteristics between residents attending top 20 and other programs ranked by reputation. Descriptive statistics, oneway ANOVA, Wilcoxon rank sum, and $\chi^{2}$ tests were utilized to compare characteristics among residents in 2009, 2013, 2016, and 2019. Significance levels were set at $p<0.05$. Univariate logistic regression was used to calculate odds ratios for all baseline characteristics associated with matching to a top 20 program according to program reputation and research productivity. Multivariate logistic regression was conducted, adjusting for significant variables in univariate regression. Sensitivity analysis was used to identify collinear variables.

\section{Results}

Data were collected on $81 \%(1,496 / 1,850)$ of ophthalmology residents in 2009, 2013, 2016, and 2019. Baseline characteristics of participants are presented in - Table 1. Residents in reputation-based top 20 and other programs differed significantly in gender, graduate degrees, international medical graduate (IMG) status, and in medical school U.S. News rank, NIH funding, mean USMLE Steps 1 and 2 scores, and region. Residents in reputation-based top 20 programs demonstrated higher $h$-indices and had produced more total, ophthalmology-related, basic science, clinical, first-author, and original research publications. Apart from gender and IMG status, baseline characteristics for residents in researchoriented top 20 and other programs showed similar differences (-Appendix 1).

Over the decade, the mean $h$-index $(0.87-1.26 ; p<0.05)$ (-Fig. 1) and mean $m$-quotient $(0.06-0.28 ; p<0.01$ ) of all first-year residents increased. The mean number of firstauthor (0.38-0.59; $p<0.01)$, ophthalmology (0.52-1.11; $p<0.01)$, original research article $(0.89-1.52 ; p<0.01)$, review $(0.08-0.19 ; p<0.05)$, and clinical $(0.41-1.11 ; p<0.01)$ publications also increased from 2009 to 2019. The proportion of residents who attended medical schools ranked in the top 20 by U.S. News decreased $(28-18 \% ; p<0.05)$.

Results of the univariate and multivariate logistic regression analyses can be seen in - Table 2. Multivariate logistic regression showed that female gender [odds ratio or OR: 1.32, 95\% CI: 1.02-1.72], having a Master's degree [OR: 2.28, 95\% CI: 1.29-4.01] or PhD [OR: 2.23, 95\% CI: 1.32-3.79], attending top 20 [OR: $5.26,95 \% \mathrm{CI}: 3.66-7.55]$ or top 40 medical schools by NIH funding [OR: $2.45,95 \%$ CI: 1.70-3.54], attending a medical school with a mean USMLE Step 2 score above 243 [OR: 1.64, 95\% CI: 1.01-2.67], attending a medical school in the Northeast [OR: 2.00, 95\% CI: 1.38-2.89], and having an $h$-index of one or more [OR: $1.92,95 \% \mathrm{CI}$ : $1.47-$ 2.51] were associated with being a resident in a top 20 program based on reputation. IMG status, medical school U.S. News rank, and mean Step 1 score and total, ophthalmology, basic science, clinical, first-author, and original research publications were dropped due to collinearity. With the exception of gender, the results of multivariate logistic regression were similar for top 20 program rankings based on NIH funding (-Appendix 2).

\section{Discussion}

This study of first-year ophthalmology residents suggests that female gender, having additional graduate degrees, attending a medical school with significant NIH funding, a high mean USMLE Step 2 score and in a Northeast location, and having an $h$-index of one or more were associated with obtaining a position in a top-ranked training program. With the exception of female gender, these characteristics were the same for residents in top 20 programs based on $\mathrm{NIH}$ funding, underscoring the relationship between reputation and research productivity. These findings can inform key stakeholders about variables linked to matching to topranked ophthalmology residency programs.

Over the past decade, the proportion of first-year ophthalmology residents who attended a top 20 medical school by reputation decreased, which may indicate that ophthalmology residency programs are placing lesser emphasis on school prestige and greater emphasis on accomplishments such as research. Indeed, the corresponding increase in the mean $h$-index and $m$-quotient over the decade suggests that ophthalmology training programs are placing a greater premium on research productivity when selecting residents. Studies in neurosurgery, orthopaedic surgery, otolaryngology, and plastic surgery have also shown increases in research productivity and publications among matched residents in the U.S. ${ }^{13,22-24}$

The residents' research productivity as medical students may be more closely related to publication quality rather than quantity. In the past decade, mean $h$-index and $m$ quotient of first-year residents increased while the mean number of publications held steady-i.e., the students were publishing similar volumes of higher quality articles with higher citation rates. The mean $m$-quotient of the residents in 2019 was 0.28 , which approaches that of instructors (0.37) and of assistant professors (0.44) in academic ophthalmology. ${ }^{25}$

In contrast to this study's findings, Bargoud et al. found that only $h$-index was associated with matching to an ophthalmology department with high research output; ${ }^{5}$ however, Bargoud et al did not consider the demographic or medical school characteristics of residents, and their smaller sample size (340) may have reduced the statistical significance of the ordinal regression performed. Additionally, they determined research output based on faculty $h$-index from a 2016 study that did not verify whether included publications were scientific. 
Table 1 First-year resident characteristics by U.S. News ophthalmology hospital ranking

\begin{tabular}{|c|c|c|c|}
\hline Baseline characteristics & $\begin{array}{l}\text { Top } 20 \text { program residents } \\
(n=420)\end{array}$ & $\begin{array}{l}\text { Other program residents } \\
(n=1,075)\end{array}$ & Test statistic, $p$-Value \\
\hline \multicolumn{4}{|l|}{ Gender, $n(\%)$} \\
\hline Male & $215(51)$ & $633(59)$ & \multirow[t]{2}{*}{$\chi^{2}=6.90, p=0.009$} \\
\hline Female & $203(49)$ & $441(41)$ & \\
\hline \multicolumn{4}{|l|}{ Graduate degrees, $n(\%)$} \\
\hline $\mathrm{MD} / \mathrm{DO}$ & $338(80)$ & $1,002(93)$ & \multirow[t]{3}{*}{$\chi^{2}=54.79, p=0.000$} \\
\hline Additional Masters & $33(8)$ & $37(3)$ & \\
\hline Additional PhD & $49(12)$ & $36(3)$ & \\
\hline \multicolumn{4}{|l|}{ IMG, $n(\%)$} \\
\hline No & $405(96)$ & $1,005(94)$ & \multirow{2}{*}{$\chi^{2}=5.37, p=0.021$} \\
\hline Yes & $15(4)$ & $67(6)$ & \\
\hline \multicolumn{4}{|l|}{ School U.S. News rank, $n(\%)$} \\
\hline Top 20 & $198(49)$ & $119(12)$ & \multirow[t]{3}{*}{$\chi^{2}=256.34, p<0.001$} \\
\hline Top 40 & $98(24)$ & $233(22)$ & \\
\hline All others & $109(27)$ & $661(66)$ & \\
\hline \multicolumn{4}{|l|}{ School NIH funding, $n(\%)$} \\
\hline Top 20 & $191(45)$ & $144(13)$ & \multirow[t]{3}{*}{$\chi^{2}=217, p<0.001$} \\
\hline Top 40 & $86(20)$ & $155(14)$ & \\
\hline All others & $143(34)$ & $776(72)$ & \\
\hline \multicolumn{4}{|l|}{ School mean USMLE Step 1 score } \\
\hline $1-216$ or $\mathrm{N} / \mathrm{A}, n(\%)$ & $48(11)$ & $315(29)$ & \multirow[t]{3}{*}{$\chi^{2}=151.33, p<0.001$} \\
\hline $217-235, n(\%)$ & $165(39)$ & $557(52)$ & \\
\hline $236+, n(\%)$ & $207(49)$ & $203(19)$ & \\
\hline \multicolumn{4}{|l|}{ School mean USMLE Step 2 score } \\
\hline $1-230$ or $N / A, n(\%)$ & $43(10)$ & $305(28)$ & \multirow[t]{3}{*}{$\chi^{2}=95.93, p<0.001$} \\
\hline $231-243, n(\%)$ & $97(23)$ & $341(32)$ & \\
\hline $244+, n(\%)$ & $280(67)$ & $429(40)$ & \\
\hline \multicolumn{4}{|l|}{ School region $^{\mathrm{a}}, n(\%)$} \\
\hline South & $123(30)$ & $375(38)$ & \multirow[t]{4}{*}{$\chi^{2}=35.05, p<0.001$} \\
\hline Northeast & $157(39)$ & $264(27)$ & \\
\hline Midwest & $67(17)$ & $257(26)$ & \\
\hline West & $58(14)$ & $96(10)$ & \\
\hline Total publications, mean (SD) & $2.24(0.17)$ & $1.13(0.09)$ & \multirow{4}{*}{$\begin{array}{l}\chi^{2}=69.95, p<0.001 \\
t=-6.32, p<0.001\end{array}$} \\
\hline $0, n(\%)$ & $172(41)$ & $682(63)$ & \\
\hline $1-3, n(\%)$ & $161(38)$ & $292(27)$ & \\
\hline $4+, n(\%)$ & $87(21)$ & $101(9)$ & \\
\hline$h$-Index, mean (SD) & $1.65(0.11)$ & $0.85(0.05)$ & \multirow{3}{*}{$\begin{array}{l}\chi^{2}=61.25, p<0.001 \\
t=-7.43, p<0.001\end{array}$} \\
\hline $0, n(\%)$ & $180(43)$ & $699(65)$ & \\
\hline $1+, n(\%)$ & $240(57)$ & $376(35)$ & \\
\hline Ophthalmology, mean (SD) & $1.16(0.14)$ & $0.68(0.07)$ & \multirow{3}{*}{$\begin{array}{l}\chi^{2}=34.21, p<0.001 \\
t=-3.29, p=0.001\end{array}$} \\
\hline $\begin{array}{r}0, n(\%) \\
1-2, n(\%)\end{array}$ & $\begin{array}{l}271(65) \\
98(23)\end{array}$ & $\begin{array}{l}850(79) \\
144(13)\end{array}$ & \\
\hline $3+, n(\%)$ & $51(12)$ & $81(8)$ & \\
\hline Basic science, mean (SD) & $1.24(0.13)$ & $0.47(0.05)$ & \\
\hline
\end{tabular}


Table 1 (Continued)

\begin{tabular}{|c|c|c|c|}
\hline Baseline characteristics & $\begin{array}{l}\text { Top } 20 \text { program residents } \\
(n=420)\end{array}$ & $\begin{array}{l}\text { Other program residents } \\
(n=1,075)\end{array}$ & Test statistic, $p$-Value \\
\hline $0, n(\%)$ & $267(64)$ & $873(81)$ & \multirow{3}{*}{$\begin{array}{l}\chi^{2}=60.88, p<0.001 \\
t=-7.07, p<0.001\end{array}$} \\
\hline $1-2, n(\%)$ & $87(21)$ & $143(13)$ & \\
\hline $3+, n(\%)$ & $66(16)$ & $59(5)$ & \\
\hline Clinical, mean (SD) & $1.00(0.11)$ & $0.66(0.07)$ & \multirow{4}{*}{$\begin{array}{l}\chi^{2}=24.34, p<0.001 \\
t=-2.69, p=0.004\end{array}$} \\
\hline $0, n(\%)$ & $264(63)$ & $810(75)$ & \\
\hline $1-2, n(\%)$ & $105(25)$ & $190(18)$ & \\
\hline $3+, n(\%)$ & $51(12)$ & $75(7)$ & \\
\hline
\end{tabular}

Abbreviations: IMG, International Medical Graduate; MD, Doctor of Medicine; MS, Master's in Science; NIH, National Institutes of Health; PhD, Doctor of Philosophy; US News, U.S. News \& World Report; USMLE, United States Medical Licensing Examination.

${ }^{a}$ This analysis excluded residents who attended medical school outside the fifty US states and District of Columbia.

bolded values demonstrate statistical significance with $p<0.05$.

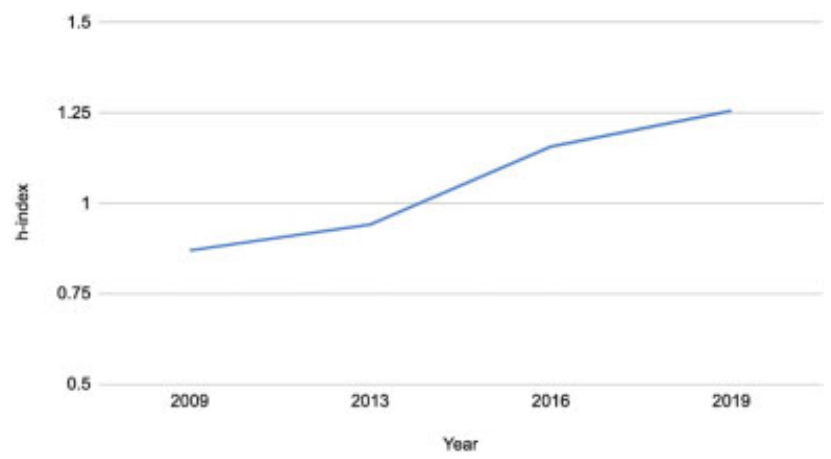

Fig. 1 Research productivity of 2009, 2013, 2016, and 2019 first-year ophthalmology residents.

This study aligns with evidence in other specialties on predictors of matching to U.S. residency programs. Similarly, previous studies in neurosurgery, orthopaedic surgery, and radiation oncology have shown that characteristics associated with matching to residency include attending a medical school with high $\mathrm{NIH}$ funding, ${ }^{26}$ having more publications, ${ }^{13,26,27}$ having additional graduate degrees, ${ }^{27}$ and achieving higher USMLE scores. ${ }^{26}$

Research productivity along with additional graduate degrees and attending a top-ranked medical school may indicate a greater propensity for an academic career; hence, applicants with these characteristics may be of greater interest to top-ranked programs, which may be more vested in educating future academicians. ${ }^{4,28-30}$ Moreover, the strong correlation between medical school's U.S. News ranking and $\mathrm{NIH}$ funding indicates a relationship between research productivity and reputation, aligning with findings from previous studies in ophthalmology and oncology. ${ }^{31,32}$

Female applicants were more likely to match to topranked ophthalmology programs; however, they comprised roughly half of residents at top 20 programs and $41 \%$ of residents at other programs. This aligns with trends in ophthalmology department and residency program leadership: $20 \%$ of the top 20 ophthalmology departments ranked by U.S. News are chaired by women compared with $10 \%$ of all departments, ${ }^{33}$ and $40 \%$ of the top 20 ophthalmology residency programs are directed by women compared with $28 \%$ of all programs. ${ }^{34}$ This trend is even more pronounced among the highest ranked programs, which produce disproportionately more residents and chairs: among the top four programs, two have female chairs and three have female residency program directors. ${ }^{33}$

As USMLE Step 1 will be graded on a pass/fail basis next year, this may increase the significance of USMLE Step 2 scores in the residency match. ${ }^{16}$ However, our multivariate analysis showed that medical school mean Step 2 score was already a stronger predictor of matching to a top-ranked program than mean Step 1 score. One reason may be that Step 2 relative to Step 1 scores have been a better predictor of board examination performance, ${ }^{35,36}$ and residency programs may have designed their admission criteria to account for the greater predictive validity of Step 2 scores.

Reasons for the association between attending a Northeastern medical school and matching to a top-ranked residency program are unclear. Only six (30\%) of the top 20 medical schools and four (20\%) of the top 20 ophthalmology residency programs by NIH funding were in the Northeast, so the association does not appear to be explained by topranked ophthalmology training programs favoring applicants from their own region.

Strengths of this study include a large sample size of 1,496 residents over a 10-year period, and the use of multiple medical school characteristics (U.S. News rankings, NIH funding, USMLE scores), residency program outcomes (U.S. News rankings, $\mathrm{NIH}$ funding), and student characteristics (gender, degrees, research productivity). Additionally, the data were obtained through searching of verified publication databases rather than self-reported sources like the National Residency Matching Program. ${ }^{37}$ Given concerns about unverifiable publications in ophthalmology and other specialties, ${ }^{13,38}$ this approach ensures that recorded data for research productivity are more accurate. The study also provides a longitudinal analysis of the role of research productivity for medical students who successfully matched into ophthalmology. 
e12 Characteristics of First-Year Residents Lin et al.

Table 2 First-year resident characteristics associated with being in a top-ranked ophthalmology program by U.S. News

\begin{tabular}{|c|c|c|}
\hline Baseline characteristics & Univariate odds ratio $(95 \% \mathrm{Cl})$ & Multivariate adjusted odds ratio $(95 \% \mathrm{Cl})$ \\
\hline \multicolumn{3}{|l|}{ Gender } \\
\hline Male & 1 [reference] & 1 [reference] \\
\hline Female & $1.36(1.08-1.70)$ & $1.32(1.02-1.72)$ \\
\hline \multicolumn{3}{|l|}{ Additional degrees } \\
\hline No additional & 1 [reference] & 1 [reference] \\
\hline Master's & $2.64(1.63-4.30)$ & $2.28(1.29-4.01)$ \\
\hline $\mathrm{PhD}$ & $4.04(2.58-6.31)$ & $2.23(1.32-3.79)$ \\
\hline \multicolumn{3}{|l|}{ IMG } \\
\hline No & 1 [reference] & \multirow[t]{2}{*}{ [dropped due to collinearity] } \\
\hline Yes & $0.56(0.31-0.98)$ & \\
\hline \multicolumn{3}{|l|}{ School U.S. News rank } \\
\hline Top 20 & $10.09(7.44-13.68)$ & \multirow[t]{3}{*}{ [dropped due to collinearity] } \\
\hline Top 40 & $2.66(1.95-3.64)$ & \\
\hline All others & 1 [reference] & \\
\hline \multicolumn{3}{|l|}{ School NIH funding } \\
\hline Top 20 & $7.20(5.44-9.53)$ & $5.26(3.66-7.55)$ \\
\hline Top 40 & $3.01(2.19-4.14)$ & $2.45(1.70-3.54)$ \\
\hline All others & 1 [reference] & 1 [reference] \\
\hline \multicolumn{3}{|c|}{ School mean USMLE Step 1 score } \\
\hline $1-216$ or $N / A$ & 1 [reference] & \multirow[t]{3}{*}{ [dropped due to collinearity] } \\
\hline $217-235$ & $1.94(1.37-2.76)$ & \\
\hline $236+$ & 6.69 (4.67-9.59) & \\
\hline \multicolumn{3}{|c|}{ School mean USMLE Step 2 score } \\
\hline $1-230$ or $\mathrm{N} / \mathrm{A}$ & 1 [reference] & 1 [reference] \\
\hline $231-243$ & $2.02(1.36-2.98)$ & $1.50(0.93-2.41)$ \\
\hline $244+$ & $4.63(3.25-6.59)$ & $1.64(1.01-2.67)$ \\
\hline \multicolumn{3}{|l|}{ School region $^{a}$} \\
\hline Midwest & 1 [reference] & 1 [reference] \\
\hline South & $1.26(0.90-1.76)$ & $1.34(0.92-1.96)$ \\
\hline Northeast & $2.28(1.63-3.18)$ & $2.00(1.38-2.89)$ \\
\hline West & $2.32(1.52-3.54)$ & $1.43(0.88-2.32)$ \\
\hline \multicolumn{3}{|l|}{$h$-index } \\
\hline 0 & 1 [reference] & 1 [reference] \\
\hline $1+$ & $2.48(1.97-3.12)$ & $1.92(1.47-2.51)$ \\
\hline \multicolumn{3}{|l|}{ Total publications } \\
\hline 0 & 1 [reference] & \multirow[t]{3}{*}{ [dropped due to collinearity] } \\
\hline $1-3$ & $2.19(1.69-2.82)$ & \\
\hline $4+$ & $3.42(2.45-4.76)$ & \\
\hline \multicolumn{3}{|l|}{ Ophthalmology } \\
\hline 0 & 1 [reference] & \multirow[t]{3}{*}{ [dropped due to collinearity] } \\
\hline $1-2$ & $2.13(1.60-2.86)$ & \\
\hline $3+$ & $1.97(1.36-2.88)$ & \\
\hline
\end{tabular}


Table 2 (Continued)

\begin{tabular}{|c|c|c|}
\hline Baseline characteristics & Univariate odds ratio $(95 \% \mathrm{CI})$ & Multivariate adjusted odds ratio $(95 \% \mathrm{Cl})$ \\
\hline \multicolumn{3}{|l|}{ Basic science } \\
\hline 0 & 1 [reference] & \multirow[t]{3}{*}{ [dropped due to collinearity] } \\
\hline $1-2$ & $1.99(1.47-2.58)$ & \\
\hline $3+$ & $3.66(2.51-5.33)$ & \\
\hline \multicolumn{3}{|l|}{ Clinical } \\
\hline 0 & 1 [reference] & \multirow[t]{3}{*}{ [dropped due to collinearity] } \\
\hline $1-2$ & $1.70(1.29-2.23)$ & \\
\hline $3+$ & $2.09(1.42-3.06)$ & \\
\hline
\end{tabular}

Abbreviations: IMG, International Medical Graduate; MD, Doctor of Medicine; MS, Master's in Science; NIH, National Institutes of Health; PhD, Doctor of Philosophy; USMLE, United States Medical Licensing Examination; US News, U.S. News \& World Report.

a Excludes residents who attended medical schools in U.S. territories, Canada, or other countries.

bolded values demonstrate statistical significance with $p<0.05$.

There are several potential weaknesses of this study. First, our population-based analysis did not include data on medical school grades, honor societies, letters of recommendation, service engagement, and interview performance. ${ }^{28}$ However, medical school grades and honor society membership are highly correlated with USMLE scores, ${ }^{39-41}$ and in this study, the mean USMLE scores from a resident's medical school were associated with obtaining a position in a topranked residency program. Second, the study excluded matched applicants who ultimately did not attend their first year of residency. However, this likely amounts to only $1 \%$ of matched ophthalmology residents. ${ }^{42}$ Third, U.S. News medical school rankings have been criticized for lacking an association with patient outcomes, reducing diversity in medical schools, and changing their ranking criteria each year. However, these rankings are associated with matching to an ophthalmology residency program and are a measure of organizational reputation. ${ }^{8,43-48}$ Moreover, U.S. News rankings were highly correlated with $\mathrm{NIH}$ funding among medical schools and residency programs. At the medical school level, this may be because the U.S. News rankings are partially based on NIH funding. ${ }^{49}$ U.S. News rankings for ophthalmology hospitals are based solely on a survey of ophthalmologists, ${ }^{50}$ although they are associated with several measures of research productivity, such as faculty publications and number of clinical trials. ${ }^{31}$ Fourth, although our measure of medical school and residency program research productivity did not consider non-NIH financial support or publication count, more NIH funding is associated with higher publication productivity. ${ }^{19,20}$ Fifth, publication count is an imperfect metric because it cannot identify relative contributions from various co-authors. ${ }^{20}$ Sixth, the study did not record data on applicants who may have taken a year off from medical school for research; however, in ophthalmology, these "research years" have not been associated with increased post-residency research productivity. ${ }^{4}$ Finally, the study recorded citation counts in 2020; since citations accrue over time, residents from 2009 and 2013 may have higher citation counts and h-indices than residents from 2016 and 2019. However, calculating an m-quotient for each resident helped address this issue.

In sum, selected individual (female gender, additional graduate degrees, and research productivity) and institutional (medical school region, NIH funding, and mean USMLE Step 2 score) characteristics were significantly associated with matching to a top-ranked ophthalmology residency program.

\section{Disclaimer}

The views expressed here are those of the authors and do not necessarily reflect the position or policy of the U.S. Department of Veterans Affairs or the U.S. government.

Conflict of Interest

None declared.

\section{References}

1 Yousuf SJ, Jones LS. Ophthalmology residency match outcomes for 2011. Ophthalmology 2012;119(03):642-646

2 San Francisco Match. Ophthalmology Residency Match Summary Report 2020. 2020

3 Yousuf SJ, Kwagyan J, Jones LS. Applicants' choice of an ophthalmology residency program. Ophthalmology 2013;120(02): 423-427

4 Cruz FM, Wang J, Joseph SS, Miller NR. Subject and academic setting of pre-residency publications as potential predictors of post-residency academic productivity in a cohort of ophthalmology residents. J Acad Ophthalmol 2018;10(01):e16-e22

5 Bargoud AR, Thangamathesvaran L, Patel VR, Henseler R, Kass W, Khouri AS. Quantifying the impact of research on matching into ophthalmology residency. J Acad Ophthalmol 2018;10(01):7

6 Driver TH, Loh AR, Joseph D, Keenan JD, Naseri A. Predictors of matching in ophthalmology residency for international medical graduates. Ophthalmology 2014;121(04):974-975.e2

7 Siatkowski RM, Mian SI, Culican SM, et al; Association of University Professors of Ophthalmology. Probability of success in the ophthalmology residency match: three-year outcomes analysis of San Francisco Matching Program Data. J Acad Ophthalmol 2018; 10(01):e150-e157

8 Loh AR, Joseph D, Keenan JD, Lietman TM, Naseri A. Predictors of matching in an ophthalmology residency program. Ophthalmology 2013;120(04):865-870 
9 Dehon E, Cruse MH, Dawson B, Jackson-Williams L. Mentoring during medical school and match outcome among emergency medicine residents. West J Emerg Med 2015;16(06):927-930

10 The Internet Archive. Wayback Machine: The Internet Archive. Accessed April 23, 2020 at: https://archive.org/

11 Doximity. Doximity. 2020. Accessed April 23, 2020 at: https:// www.doximity.com/

12 LinkedIn. LinkedIn 2020. Accessed April 23, 2020 at: https:// www.linkedin.com/

13 Wadhwa H, Shah SS, Shan J, et al. The neurosurgery applicant's "arms race": analysis of medical student publication in the Neurosurgery Residency Match. J Neurosurg 2019 (e-pub ahead of print). Doi: 10.3171/2019.8.JNS191256

14 Hirsch JE. An index to quantify an individual's scientific research output. Proc Natl Acad Sci U S A 2005;102(46):16569-16572

15 U.S. News \& World Report. Best Medical Schools: Research: US News and World Report. 2020. Available at: https://www. usnews.com/best-graduate-schools/top-medical-schools/researchrankings

16 Pershing S, Co JPT, Katznelson L. The new USMLE step 1 paradigm: an opportunity to cultivate diversity of excellence. Acad Med 2020;95(09):1325-1328

17 U.S. Census Bureau. Cartographer Census Regions and Divisions of the United States: U.S. Census Bureau. 2020

18 Morse R, Vega-Rodriguez J, Castonguay A, Brooks E. Methodology: 2021 Best Medical Schools Rankings New York. NY: U.S. News \& World Report; 2020 Available at: https://www.usnews.com/education/best-graduate-schools/articles/medical-schools-methodology

19 Svider PF, Lopez SA, Husain Q Bhagat N, Eloy JA, Langer PD. The association between scholarly impact and National Institutes of Health funding in ophthalmology. Ophthalmology 2014;121(01): 423-428

20 Yang J, Vannier MW, Wang F, et al. A bibliometric analysis of academic publication and NIH funding. J Informetrics 2013;7(02): 318-324

21 StataCorp. Stata Statistical Software: Release 16. College Station. TX: StataCorp, LLC; 2019

22 Abraham JT, Nguyen AV, Weber RA. Integrated plastic surgery residency applicant trends and comparison with other surgical specialties. Ann Plast Surg 2018;80(02):164-170

23 DePasse JM, Palumbo MA, Eberson CP, Daniels AH. Academic characteristics of orthopaedic surgery residency applicants from 2007 to 2014. J Bone Joint Surg Am 2016;98(09):788-795

24 Bowe SN, Schmalbach CE, Laury AM. The state of the otolaryngology match: a review of applicant trends, "impossible" qualifications, and implications. Otolaryngol Head Neck Surg 2017;156 (06):985-990

25 Thiessen CR, Venable GT, Ridenhour NC, Kerr NC. Publication productivity for academic ophthalmologists and academic ophthalmology departments in the united states: an analytical report. J Clin Acad Ophthalmol 2016;8(01):e19-e29

26 SchrockJB, Kraeutler MJ, Dayton MR, McCarty EC. A comparison of matched and unmatched orthopaedic surgery residency applicants from 2006 to 2014: data from the National Resident Matching Program. J Bone Joint Surg Am 2017;99(01):e1

27 Jang S, Rosenberg SA, Hullett C, Bradley KA, Kimple RJ. Beyond 'charting outcomes' in the radiation oncology match: analysis of self-reported applicant data. Med Educ Online 2018;23(01): 1489691

28 Nallasamy S, Uhler T, Nallasamy N, Tapino PJ, Volpe NJ. Ophthalmology resident selection: current trends in selection criteria and improving the process. Ophthalmology 2010;117(05):1041-1047

29 Valikodath NG, Fausett BV, Oren GA, Whitney K, Woodward MA, Mian SI. Impact of a dedicated research rotation during ophthalmology residency. J Acad Ophthalmol 2017;9(01):e1-e6
30 Hark L, Haller JA, Murchison AP, et al. A clinical vision research training and mentoring program as a model for ophthalmology and other medical specialties: implementation and evaluation. J Acad Ophthalmol 2017;09(01):e13-e20

31 Lin JC, Chen AJ, Scott IU, Greenberg PB. US news \& world report ophthalmology hospital rankings and research productivity. J Acad Ophthalmol 2021;13(01):e45-e50

32 Prasad V, Goldstein JA. US News and World Report cancer hospital rankings: do they reflect measures of research productivity? PLoS One 2014;9(09):e107803

33 Dotan G, Qureshi HM, Gaton DD. Chairs of United States Academic Ophthalmology Departments: a descriptive analysis and trends. Am J Ophthalmol 2018;196:26-33

34 Kloosterboer A, Yannuzzi NA, Gedde SJ, Sridhar J. Residency Program Directors of United States Ophthalmology Programs: a descriptive analysis. Am J Ophthalmol 2020;209:71-76

35 Harmouche E, Goyal N, Pinawin A, Nagarwala J, Bhat R. USMLE scores predict success in ABEM initial certification: a multicenter study. West J Emerg Med 2017;18(03):544-549

36 Spurlock DR Jr, Holden C, Hartranft T. Using United States Medical Licensing Examination( $\left.{ }^{\circledR}\right)$ (USMLE) examination results to predict later in-training examination performance among general surgery residents. J Surg Educ 2010;67(06):452-456

37 National Resident Matching Program. Charting Outcomes in the Match. Characteristics of U.S. MD Seniors Who Matched to Their Preferred Specialty in the 2020 Main Residency Match. Washington, DC: NRMP; 2020

38 Tamez HM, Tauscher R, Brown EN, Wayman L, Mawn LA. Rate of unverifiable publications among ophthalmology residency applicants invited to interview. JAMA Ophthalmol 2018;136(06):630-635

39 Gauer JL, Jackson JB. The association between United States Medical Licensing Examination scores and clinical performance in medical students. Adv Med Educ Pract 2019;10:209-216

40 Ghaffari-Rafi A, Lee RE, Fang R, Miles JD. Multivariable analysis of factors associated with USMLE scores across U.S. medical schools. BMC Med Educ 2019;19(01):154

41 Specter S, Kahn MJ, Lazarus C, et al. Gold Humanism Honor Society Election and Academic Outcomes: a 10-institution study. Fam Med 2015;47(10):770-775

42 Hatton MP, Loewenstein J. Attrition from ophthalmology residency programs. Am J Ophthalmol 2004;138(05):863-864

43 Bastedo MN, Bowman NAUS. News \& World Report College Rankings: modeling institutional effects on organizational reputation. Am J Educ 2010;116(02):163-183

44 Chakraborti C, Woodson MJ, Kahn MJ. Relationship between Medical School Diversity and participation in the US News and World Report Survey. J Natl Med Assoc 2021;113(03):260-264

45 Tsugawa Y, Blumenthal DM, Jha AK, Orav EJ, Jena AB. Association between physician US News \& World Report medical school ranking and patient outcomes and costs of care: observational study. BMJ 2018;362:k3640

46 Tancredi DJ, Bertakis KD, Jerant A. Short-term stability and spread of the U.S. News \& World Report primary care medical school rankings. Acad Med 2013;88(08):1107-1115

47 McGaghie WC. America's Best Medical Schools: a renewed critique of the U.S. news \& world report rankings. Acad Med 2019;94 (09):1264-1266

48 McGaghie WC, Thompson JA. America's best medical schools: a critique of the U.S. News \& World Report rankings. Acad Med 2001;76(10):985-992

49 Morse R, Vega-Rodriguez J, Castonguay A, Brooks E. Methodology: 2021 Best Medical Schools Rankings 2020 Mar. 2021

50 U.S. News Staff. FAQ: How and Why We Rank and Rate Hospitals: U.S. News \& World Report. 2019 Jul. Accessed June 5 , 2020 at: https://health.usnews.com/health-care/best-hospitals/articles/faq-how-and-why-we-rank-and-rate-hospitals 
Appendix 1 First-year resident characteristics by ophthalmology hospital ranking according to NIH funding

\begin{tabular}{|c|c|c|c|}
\hline Baseline characteristics & $\begin{array}{l}\text { Top } 20 \text { program } \\
\text { residents }(n=377)\end{array}$ & $\begin{array}{l}\text { Other program } \\
\text { residents }(n=1,118)\end{array}$ & Test statistic, $p$-Value \\
\hline \multicolumn{4}{|l|}{ Gender, $n(\%)$} \\
\hline Male & $209(55)$ & $639(57)$ & \multirow[t]{2}{*}{$\chi^{2}=0.40, p=0.526$} \\
\hline Female & $168(46)$ & $476(43)$ & \\
\hline \multicolumn{4}{|l|}{ Graduate degrees, $n(\%)$} \\
\hline $\mathrm{MD} / \mathrm{DO}$ & $285(76)$ & $1,055(94)$ & \multirow[t]{3}{*}{$\chi^{2}=108.60, p<0.001$} \\
\hline Additional Master's & $38(10)$ & $32(3)$ & \\
\hline Additional PhD & $54(14)$ & $31(3)$ & \\
\hline \multicolumn{4}{|l|}{ IMG, $n(\%)$} \\
\hline No & $357(95)$ & $1,053(94)$ & \multirow[t]{2}{*}{$\chi^{2}=0.04, p=0.851$} \\
\hline Yes & $20(5)$ & $62(6)$ & \\
\hline \multicolumn{4}{|l|}{ School US News rank, $n$ (\%) } \\
\hline Top 20 & $97(27)$ & $673(64)$ & \multirow[t]{3}{*}{$\chi^{2}=206.86, p<0.001$} \\
\hline Top 40 & $88(25)$ & $233(22)$ & \\
\hline All others & $172(48)$ & $145(14)$ & \\
\hline \multicolumn{4}{|l|}{ School NIH funding, $n(\%)$} \\
\hline Top 20 & $159(42)$ & $176(16)$ & \multirow[t]{3}{*}{$\chi^{2}=146.75, p<0.001$} \\
\hline Top 40 & $80(21)$ & $161(14)$ & \\
\hline All others & $138(37)$ & $781(70)$ & \\
\hline \multicolumn{4}{|l|}{ School mean USMLE Step 1 score } \\
\hline $1-216$ or $N / A, n(\%)$ & $48(13)$ & $315(28)$ & \multirow[t]{3}{*}{$\chi^{2}=91.07, p<0.001$} \\
\hline $217-235, n(\%)$ & $158(42)$ & $564(50)$ & \\
\hline $236+, n(\%)$ & $171(45)$ & $239(21)$ & \\
\hline \multicolumn{4}{|l|}{ School mean USMLE Step 2 score } \\
\hline $1-230$ or $N / A, n(\%)$ & $43(11)$ & $305(27)$ & \multirow[t]{3}{*}{$\chi^{2}=73.59, p<0.001$} \\
\hline $231-243, \mathrm{n}(\%)$ & $86(23)$ & $352(31)$ & \\
\hline $244+, \mathrm{n}(\%)$ & $248(66)$ & $461(41)$ & \\
\hline \multicolumn{4}{|l|}{ School region $^{\mathrm{a}}, n(\%)$} \\
\hline Midwest & $69(19)$ & $255(25)$ & \multirow[t]{4}{*}{$\chi^{2}=26.37, p<0.001$} \\
\hline South & $100(28)$ & $398(38)$ & \\
\hline Northeast & $137(38)$ & $284(27)$ & \\
\hline West & $51(14)$ & $103(10)$ & \\
\hline Total publications, mean (SD) & $2.38(3.68)$ & $1.13(2.77)$ & \multirow{4}{*}{$\begin{array}{c}\chi^{2}=69.48, p<0.001 \\
t=-6.95, p<0.001\end{array}$} \\
\hline $0, n(\%)$ & $157(42)$ & $697(62)$ & \\
\hline $1-3, n(\%)$ & $133(35)$ & $320(29)$ & \\
\hline $4+, n(\%)$ & $87(23)$ & $101(9)$ & \\
\hline h-index, mean (SD) & $1.83(2.54)$ & $0.82(1.59)$ & \multirow{3}{*}{$\begin{array}{c}\chi^{2}=52.11, p<0.001 \\
t=-9.10, p<0.001\end{array}$} \\
\hline $0, n(\%)$ & $162(43)$ & $717(64)$ & \\
\hline $1+, n(\%)$ & $215(57)$ & $401(36)$ & \\
\hline Ophthalmology publications, mean (SD) & $1.22(2.94)$ & $0.68(2.36)$ & \multirow{4}{*}{$\begin{array}{l}\chi^{2}=28.29, p<0.001 \\
t=-3.62, p=0.003\end{array}$} \\
\hline $0, n(\%)$ & $246(65)$ & $875(78)$ & \\
\hline $1-2, n(\%)$ & $78(21)$ & $164(15)$ & \\
\hline $3+, n(\%)$ & $53(14)$ & $79(7)$ & \\
\hline
\end{tabular}


Appendix 1 (Continued)

\begin{tabular}{|c|c|c|c|}
\hline Baseline characteristics & $\begin{array}{l}\text { Top } 20 \text { program } \\
\text { residents }(n=377)\end{array}$ & $\begin{array}{l}\text { Other program } \\
\text { residents }(n=1,118)\end{array}$ & Test statistic, $p$-Value \\
\hline Basic science publications, mean (SD) & $1.40(2.88)$ & $0.44(1.37)$ & \multirow{4}{*}{$\begin{array}{c}\chi^{2}=73.96, p<0.001 \\
t=-8.64, p<0.001\end{array}$} \\
\hline $0, n(\%)$ & $236(63)$ & $904(81)$ & \\
\hline $1-2, n(\%)$ & $73(19)$ & $157(14)$ & \\
\hline $3+, n(\%)$ & $68(18)$ & $57(5)$ & \\
\hline Clinical publications, mean (SD) & $0.98(2.21)$ & $0.68(2.16)$ & \multirow{4}{*}{$\begin{array}{c}\chi^{2}=14.24, p<0.001 \\
t=-2.28, p=0.023\end{array}$} \\
\hline $0, n(\%)$ & $245(65)$ & $829(74)$ & \\
\hline $1-2, n(\%)$ & $86(23)$ & 209 (19) & \\
\hline $3+, n(\%)$ & $46(12)$ & $80(7)$ & \\
\hline
\end{tabular}

Abbreviations: IMG, International Medical Graduate; MD, Doctor of Medicine; MS, Master's in Science; NIH, National Institutes of Health; PhD, Doctor of Philosophy; USMLE, United States Medical Licensing Examination; U.S. News rank, U.S. News \& World Report 2021 Medical School Research Rank. ${ }^{a}$ This analysis excluded residents who attended medical school outside the fifty US states and District of Columbia.

bolded values demonstrate statistical significance with $p<0.05$.

Appendix 2 First-year resident characteristics associated with being in a top-ranked research-oriented ophthalmology program

\begin{tabular}{|c|c|c|}
\hline Baseline characteristics & Univariate odds ratio $(95 \% \mathrm{Cl})$ & Multivariate adjusted odds ratio $(95 \% \mathrm{Cl})$ \\
\hline \multicolumn{3}{|l|}{ Gender } \\
\hline Male & 1 [reference] & \\
\hline Female & $1.08(0.85-1.37)$ & \\
\hline \multicolumn{3}{|l|}{ Additional degrees } \\
\hline No additional & 1 [reference] & 1 [reference] \\
\hline Master's & $4.40(2.70-7.16)$ & $3.87(2.23-6.73)$ \\
\hline $\mathrm{PhD}$ & $6.45(4.07-10.22)$ & $4.48(2.61-7.68)$ \\
\hline \multicolumn{3}{|l|}{ IMG } \\
\hline No & 1 [reference] & \\
\hline Yes & $0.95(0.57-1.60)$ & \\
\hline \multicolumn{3}{|l|}{ School U.S. News rank } \\
\hline & $8.23(6.06-11.19)$ & \multirow[t]{3}{*}{ [dropped due to collinearity] } \\
\hline Top 20 & $2.62(1.89-3.63)$ & \\
\hline $\begin{array}{l}\text { Top } 40 \\
\text { All others }\end{array}$ & 1 [reference] & \\
\hline \multicolumn{3}{|l|}{ School NIH funding } \\
\hline Top 20 & $5.11(3.86-6.77)$ & $3.63(2.51-5.24)$ \\
\hline Top 40 & $2.81(2.03-3.89)$ & $2.16(1.48-3.15)$ \\
\hline All others & 1 [reference] & 1 [reference] \\
\hline \multicolumn{3}{|c|}{ School mean USMLE Step 1 score } \\
\hline $1-216$ or $\mathrm{N} / \mathrm{A}$ & 1 [reference] & \multirow[t]{3}{*}{ [dropped due to collinearity] } \\
\hline $217-235$ & $1.84(1.29-2.61)$ & \\
\hline $236+$ & $4.70(3.27-6.74)$ & \\
\hline \multicolumn{3}{|c|}{ School mean USMLE Step 2 score } \\
\hline $1-230$ or $\mathrm{N} / \mathrm{A}$ & 1 [reference] & 1 [reference] \\
\hline $231-243$ & $1.73(1.17-2.58)$ & $2.16(1.48-3.15)$ \\
\hline $244+$ & $3.82(2.68-5.44)$ & $3.63(2.51-5.24)$ \\
\hline
\end{tabular}


Appendix 2 (Continued)

\begin{tabular}{|c|c|c|}
\hline Baseline characteristics & Univariate odds ratio $(95 \% \mathrm{Cl})$ & Multivariate adjusted odds ratio $(95 \% \mathrm{Cl})$ \\
\hline \multicolumn{3}{|l|}{ School region $^{a}$} \\
\hline Midwest & 1 [reference] & 1 [reference] \\
\hline South & $0.93(0.66-1.31)$ & $0.99(0.67-1.44)$ \\
\hline Northeast & $1.78(1.28-2.49)$ & $1.54(1.07-2.23)$ \\
\hline West & $1.83(1.19-2.81)$ & $1.17(0.72-1.91)$ \\
\hline \multicolumn{3}{|l|}{ h-Index } \\
\hline 0 & 1 [reference] & 1 [reference] \\
\hline $1+$ & $2.37(1.87-3.01)$ & $1.65(1.25-2.17)$ \\
\hline \multicolumn{3}{|l|}{ Total publications } \\
\hline 0 & 1 [reference] & \multirow[t]{3}{*}{ [dropped due to collinearity] } \\
\hline $1-3$ & $1.85(1.41-2.41)$ & \\
\hline $4+$ & $3.82(2.74-5.35)$ & \\
\hline \multicolumn{3}{|l|}{ Ophthalmology } \\
\hline 0 & 1 [reference] & \multirow[t]{3}{*}{ [dropped due to collinearity] } \\
\hline $1-2$ & $1.69(1.25-2.29)$ & \\
\hline $3+$ & $2.39(1.64-3.47)$ & \\
\hline \multicolumn{3}{|l|}{ Basic science } \\
\hline 0 & 1 [reference] & \multirow[t]{3}{*}{ [dropped due to collinearity] } \\
\hline $1-2$ & $1.78(1.30-2.43)$ & \\
\hline $3+$ & $4.57(3.13-6.68)$ & \\
\hline \multicolumn{3}{|l|}{ Clinical } \\
\hline 0 & 1 [reference] & \multirow[t]{3}{*}{ [dropped due to collinearity] } \\
\hline $1-2$ & $1.39(1.04-1.86)$ & \\
\hline $3+$ & $1.95(1.32-2.87)$ & \\
\hline
\end{tabular}

Abbreviations: IMG, International Medical Graduate; MD, Doctor of Medicine; MS, Master's in Science; NIH, National Institutes of Health; PhD, Doctor of Philosophy; USMLE, United States Medical Licensing Examination; U.S. News rank, U.S. News \& World Report 2021 Medical School Research Rank. a Excludes residents who attended medical schools in U.S. territories, Canada, or other countries. 